Bulte, E., List, J.A., \& Strazicich, M.C. (2007). Regulatory Federalism and the Distribution of Air Pollutant Emissions. Journal of Regional Science, February 2007, Vol. 47, No. 1, 155-178 (with Erwin Bulte and John List). Published by Wiley-Blackwell (ISSN: 0022-4146). DOI: 10.1111/j.1467-9787.2007.00504.x.

\title{
Regulatory Federalism and the Distribution of Air Pollutant Emissions
}

Erwin Bulte, John A. List, and Mark C. Strazicich

\begin{abstract}
Recent empirical work suggests that (i) incomes are converging through time, and (ii) income and pollution levels are linked. This paper weds these two literatures by examining the spatial and temporal distribution of pollution. After establishing that theoretical predictions about whether pollution will converge are critically linked to certain structural parameters, we explore pollution convergence using state-level data on two important pollutants-nitrogen oxides and sulfur oxides-from 1929 to 1999. We find stronger evidence of converging emission rates during the federal pollution control years (1970-1999) than during the local control years (1929-1969). These results suggest that income convergence alone may not be sufficient to induce convergence of pollutant emissions.
\end{abstract}




\section{INTRODUCTION}

Examining the appropriate division of functions among different levels of government has increased in popularity during the past two decades. In academic circles, Musgrave's (1959) seminal treatment of the public sector served to stimulate interest in the federalist nature of governmental structures some four decades ago. Musgrave divided the public fiscal department into three branches: allocation, distribution, and stabilization; but perhaps the area attracting the most attention of late is the allocation branch-determining the optimal institutional arrangements for the provision of public goods and services (see, e.g., Oates, 1991, 2002). Within this large scope of duties lies the responsibility for setting and enforcing environmental regulations.

A hotly debated issue revolves around the merits of regulation at each level: some conjecture that in a second-best world where initial distortions are present, locally determined environmental regulations are likely to be suboptimal when jurisdictions compete with each other to attract capital (Oates and Schwab, 1988). Alternatively, others (notably Wilson, 1996) provide theoretical arguments that suggest localities may either "race to the top" (the NIMBY phenomenon) or "race to the bottom" when setting environmental regulations. Regulatory federalism issues are much more than academic curiosity, as concern over a race to the bottom led the U.S. government to create the environmental protection agency (EPA) in 1970 and to pass subsequent legislation establishing national ambient standards for air and water quality (List and Gerking, 2000).

The ongoing debate also has implications beyond policy circles: in both a positive and normative perspective the issue has considerable merits. First, equity may be important. Although a literature is developing that examines the distributional characteristics of pollution (see, e.g., Brooks and Sethi, 1997; Arora and Cason, 1999; List, 1999; Millimet and List, 2003; Strazicich and List, 2003), little has been done to link the effects of centralization (or devolution) of environmental authority to the distribution of pollutant emissions. Considerable evidence has mounted that suggests certain pollutants have threshold effects (e.g., Arrow et al., 1995), and therefore health affects from higher pollution levels are best represented by, for example, an exponential function. Accordingly, ceteris paribus, an optimal spatial pattern of pollution would favor dilution rather than agglomeration.

Second, Solow's (1956) neoclassical growth model implies that given similar economy characteristics of population growth, savings, depreciation, and technology, per capita incomes will converge across countries and regions. Given permanent differences in these characteristics, the Solow model predicts that incomes will converge "conditionally" to their own steady-state, or "compensating differential." Thus, the Solow model predicts that relatively poor regions will catch up to relatively rich regions, although permanent income differences will likely remain. Recent empirical evidence suggests that incomes are indeed converging across U.S. states and regions (e.g., Barro and Sala-i-Martin, 1991; Carlino and Mills, 1993, 1996; Evans and Karras, 1996a,b; Loewy and Papell, 1996; Quah, 1996; Webber, White, and Allen, 2005). If one links incomes and environmental outcomes via the Coase theorem (Hamilton, 1995), 
these findings leave open the possibility that income levels adjusted for environmental quality will also converge (see also Brock and Taylor, 2004).

The theoretical perspective on these matters is ambiguous. Even in the context of a simple Solow growth model one might find converging or diverging pollution levels. Adding complicating (but realistic) features like interjurisdictional competition for capital adds to the potentially rich set of results that may be obtained in theory. With such conflicting predictions from theory, we turn to an empirical analysis to explore whether pollutant emissions are converging across theU.S. states in the 20th century.We present evidence concerning these issues by examining 1929-1999 state-level data on emissions of sulfur dioxides and nitrogen oxides. To provide an indication of the effects of centralization on the distribution of emissions, we split the sample into two regimes-1929-1969 and 1970-1999 - and use time series tests with structural breaks to test for converging emissions. The early sample period represents an era of state and local pollution control whereas the latter years correspond to an era of significant federal presence. 1

We find that during the years of state pollution control, emissions of pollutants for about one-half of the states are not converging. Interestingly, after centralization of environmental standards, emissions are converging in about three-quarters of the states. These results are consistent with the Solow model described in Section 2, but also suggest the possibility of environmental dumping — competition between localities to attract capital investment (see, e.g., Jeppesen, List, and Folmer, 2002). According to this perspective, poorer regions may have traded environmental quality for relative income gains prior to 1970 , but were restricted in their ability to do so after 1970. Regardless of interpretation, importantly, this result suggests that convergence of income may not be sufficient to induce convergence of some pollutant types. Our findings are consistent with the conjecture of Brooks and Sethi (1997) that "without [nation-wide ambient] standards, the disparities faced by certain subpopulations in the United States will not diminish appreciably in the foreseeable future." Although our data are aggregate in nature, whereas Brooks and Sethi (1997) use disaggregate data, it is interesting that their intuition is consistent with our empirical results.

The remainder of our paper is organized as follows. Section 2 sketches the main linkages between income growth and pollution when environmental regulation is implemented at the state and federal level. Section 3 describes the data. Section 4 presents the empirical methods and results. Section 5 provides concluding remarks.

\section{POLLUTION PATTERNS AND CONVERGENCE}

An interesting body of literature examining the determinants of spatial pollution patterns has emerged recently (Gianessi, Peskin, and Wolff, 1979; Hamilton, 1995; Brooks and Sethi, 1997; Arora and Cason, 1999). Adding to this literature, we note that there are two distinct empirical observations that are germane to the issue of pollution convergence. First, as mentioned in the previous section, state and regional income levels are generally converging over 
time. Second, there is evidence of an inverted $U$-shaped relation between income and certain pollutants-the Environmental Kuznets Curve (EKC).2 Grossman and Krueger (1995) provide some support in favor of the EKC for local stock pollutants, and List and Gallet (1999) and Millimet et al. (2003) find some evidence of such a relationship for emissions of NOx and SO2 across U.S. states (we should note, however, that Azomahou, Laisney, and Nguyen Van (2006) use a nonparametric panel data model to show that this nonmonotonic relation does not hold for $\mathrm{CO} 2$ - a global stock pollutant). The combination of income convergence and the EKC necessarily implies that theory produces ambiguous predictions about whether pollution profiles are converging or diverging.

The intuition is simple (a formal derivation is available in the Appendix). Consider a simple Solow growth model where pollution is a byproduct of consumption—but may be mitigated by abatement—and where a "mechanism" is built into the model to ensure an inverted $U$-shaped relation between income and pollution. Following the literature, this mechanism may be driven by political economy considerations, increasing returns to scale in abatement, or technical change. With equilibrium income growth governed by exogenous technical change in production, there must be absolute convergence of pollution in the long term. Pollution levels may fall to zero if incomes get sufficiently high or approach arbitrary low levels, but eventually they will converge.

The "not-so-long-term" perspective is rather different, however. Absolute pollution levels may converge or diverge-both during the approach to the balanced growth paths and along balanced growth paths. States with different income levels will converge towards their own balanced income and pollution path, but this implies that for some states (with "low" incomes) the growth rate of pollutants will be positive whereas for other states (with "high" incomes) the growth rate is negative. Pollution levels may converge or diverge, depending on income differences between states. When such income differences are small, convergence will occur; when differences are large, pollution levels may diverge.

We will briefly discuss two extensions of this basic story, highlighting that the picture becomes even less clear when adding further realistic elements to the model. First, we may consider the case where environmental regulation is the responsibility of the federal government rather than the state, as has been effectively the case in the U.S. since 1970.3 As shown by Andreoni and Levinson (2001), when the federal government maximizes the sum of state utilities and accounts for spillover costs, the shape of the pollution/income path does not change. While optimal consumption (abatement) levels are lower (higher) from a federal perspective when compared to the local optimum (so that the level of the pollution/income path is affected); the pollution path's shape does not change. In the long run absolute convergence is expected; in the short and medium run convergence towards the balanced pollution path occurs, and absolute pollution levels in different states may diverge or converge.

Second, we may consider what happens when capital is a mobile production factor. In a first-best world, states will not lower taxes to attract capital-doing so would reduce local welfare and induce Tiebout migration (where residents "vote with their feet"; see Tiebout, 1956, but also Oates and Schwab, 1988, and Wellisch, 2000).4 Real-life politics, however, takes place in a context littered 
with pre-existing distortions. Key assumptions of the benchmark model are likely violated in reality. Examples include lack of market power in national capital markets, absence of strategic interaction with respect to other localities, and access to a perfect range of regulatory instruments. In such a context, "optimal" local regulation might well be different from the first-best benchmark, as environmental policies should take distortions into account.

For example, competition for capital in a world in which the social return to capital exceeds the private return could give rise to sub-optimally low taxes. This might be caused by capital taxation, but there are many other potential distortions. For example, in the case of unemployment due to wage rigidities, it may be rational for governments to choose "low" tax levels to reduce unemployment costs (Wilson, 1996).5 If tighter environmental regulation decreases the rate of return on investment, then Krugman's (1997) quip becomes important: "any country which has a pre-existing tendency to attract too little capital will have an incentive to avoid such regulations; whereas a collective, international decision to impose higher standards would not lead to capital flight, because the capital would have nowhere to go."6

The theoretical insight that local policies may be distorted is consonant with the following quote, which highlights that state policymakers will trade off environmental quality to attract manufacturing firms and jobs:

"We have traded the environment for jobs. . . where the environment became either totally or partially damaged, in some instances permanently. However, we have no regrets, no remorse."-Edwin Edwards, Governor of Louisiana, 1979.

If states in a second-best context compete for mobile capital and, in terms of environmental stringency, "race to the bottom," local economies are not on a single equilibrium income and pollution path. Specifically, when local standards or taxes are relaxed, the economy shifts to an increasingly higher pollution path. If only a subset of states is engaged in competition, then divergence of pollution is expected to occur. In this case, some states willingly "drift" from one pollution/income path to the next while others follow a single path over time. This provides an alternative prediction for the intertemporal behavior of pollution paths.

Writing about the potential efficiency losses associated with interjurisdictional competition, Oates (2002) concludes that "we are badly in need of empirical estimates of these distortions." The analysis below attempts to provide a first step in this direction.

\section{DATA DESCRIPTION}

We empirically analyze the spatial distribution of air pollution emissions by examining the time-series convergence proposition suggested in Carlino and Mills (1993). Described more fully below, we first examine the natural log of the ratio of state per capita emissions relative to average per capita emissions to test if shocks are permanent or temporary.7 If shocks to the log ratio are 
temporary, then the series is "stochastically converging;" alternatively, if shocks are permanent, then divergence is evident. As noted by Carlino and Mills (1993), although stochastic convergence is necessary for convergence to occur, it is not sufficient. 8 They note that the log relative series should also be examined to see if trending towards the mean. Since this time series test for "-_convergence" does not include a measure of the initial value of the log emissions series on the right-hand side of the regression, the test is not subject to criticisms noted for the cross-section test.9 Using each testing procedure, we examine both preand post-1970 emission rates.

To test for converging emissions, we analyze state per capita emissions of two criteria air pollutants: sulfur dioxide (SO2) and nitrogen oxide (NOx) (see also List, 1999; List and Gallet, 1999; and Millimet et al., 2003 who make use of these data). These choices are mainly driven by data considerations, as no other emissions data that we are aware of span from 1929 to 1999, but they also offer interesting pollutants to examine. The original Clean Air Act Amendments of 1970 targeted SO2 early on due to its adverse health effects on humans and its negative impact through the deposition of acid rain. Quantified health effects associated with prolonged exposures to SO2 include changes in pulmonary functions, respiratory ailments, and in extreme cases premature death. SO2 can also significantly damage crops and man-made structures; total global damage estimates range in the hundreds of millions of dollars (U.S. EPA, 1997). These and other deleterious effects associated with SO2 emissions led policymakers to take an early strong stance against emitters of SO2 in an effort to substantially curb emissions (Gianessi et al., 1979).NOx, onthe other hand, is a precursor to ozone, can induce respiratory effects in humans, form particulate nitrates, and is a component of acid rain.

Our emissions data are available for each of the 48 contiguous states over the period 1929-1994 and come from National Air Pollutant Emission Trends (U.S. EPA, 1994). The EPA kindly provided additional data covering the period 1995-1999. The emission-estimating methodologies fall into two categories. From 1929-1984 emissions are calculated using a "top-down" approach, whereby state-level information on different fuel type use was entered in an algorithm to determine the various pollution emissions. For example, state level data on coal consumption was entered in an "emission factor" equation to determine the pounds of SO2 produced for each ton of coal consumed. Emission factors were adjusted by the EPA for differences in age and type of utility, among other factors, when possible. Prior to the 1970s, there were fewer differences in emissions due to age of utility and control factors. While the primary fuel consumption measure was at the state-level, in some cases such data was not available. In this case, national fuel consumption data was employed to estimate state-level emissions as a fraction of the national.10 From 1985 to 1999, emissions are estimated using a "bottom-up" methodology whereby emissions are derived at the plant or county level and aggregated to the state level. Note that utilizing data relative to the mean, and allowing for structural breaks, mitigates problems associated with combining two potentially heterogeneous data sets. 
TABLE 1: Aggregate U.S. $\mathrm{SO}_{2}$ and $\mathrm{NO}_{\mathrm{x}}$ Emissions (in Thousands of Short Tons)

\begin{tabular}{lcc}
\hline \hline Year & $\mathrm{SO}_{2}$ emissions & $\mathrm{NO}_{\mathrm{x}}$ emissions \\
\hline 1970 & 31,161 & 20,625 \\
1971 & 29,686 & 21,227 \\
1972 & 30,389 & 22,381 \\
1973 & 31,756 & 23,118 \\
1974 & 30,035 & 22,317 \\
1975 & 28,011 & 21,889 \\
1976 & 28,426 & 23,258 \\
1977 & 28,605 & 23,986 \\
1978 & 26,899 & 24,253 \\
1979 & 26,953 & 23,812 \\
1980 & 25,905 & 23,281 \\
1981 & 24,527 & 23,070 \\
1982 & 23,140 & 22,496 \\
1983 & 22,541 & 22,364 \\
1984 & 23,470 & 23,172 \\
1985 & 23,230 & 22,859 \\
1986 & 22,442 & 22,348 \\
1987 & 22,204 & 22,403 \\
1988 & 22,647 & 23,618 \\
1989 & 22,785 & 23,222 \\
1990 & 22,433 & 23,038 \\
1991 & 22,068 & 22,672 \\
1992 & 21,836 & 22,847 \\
1993 & 21,517 & 23,276 \\
1994 & 21,118 & 23,615 \\
\hline & &
\end{tabular}

To indicate the degree of progress that has been made to curb emissions in the last three decades, we present Table 1, which provides a breakdown of the national emissions estimates from 1970 to 1994 . The data presented show that SO2 emissions were significantly declining after federal intervention: between 1970 and 1994 raw SO2 emissions decreased from 31,161 thousand short tons to 21,118 thousand short tons, a reduction of nearly 33 percent. Alternatively, while NOx emissions increased by over 180 percent from 1940 to 1970, emissions since 1970 have leveled off at about 23 million short tons since 1973. The result for $\mathrm{SO} 2$ is consistent with our prediction that centralization lowers aggregate emissions; while the data show that centralization did not decrease the level of NOx, it did significantly lower its growth rate. Yet the limited progress that has been made to reduceNOx emissions highlights why ozone has attracted the most regulatory attention of late. While these data patterns are interesting in their own right, they provide little guidance about the temporal distribution of pollutants. To examine whether emissions are converging, further testing using state-level data is necessary. 


\section{EMPIRICAL METHODOLOGY AND RESULTS}

\section{Stochastic Convergence}

The null hypothesis that state emission levels are diverging is first examined by testing for a unit root in the logarithm of pollution per capita in state $i$ relative to the average of all states. Stochastic convergence implies that shocks to state pollution relative to the average will be temporary, implying that the log-relative series is a stationary process. Following a shock to the system, per capita pollution in state $i$ can move further above or below the national average only temporarily. Alternatively, under the unit root null hypothesis, relative emissions are nonstationary, suggesting that shocks have permanent effects. Following a shock to per capita emissions in state $i$, under the null hypothesis, there is no tendency to return toward the average, implying that emissions will diverge. Since a state-specific constant term is included in the test, stochastic convergence is consistent with conditional convergence.

To illustrate, we let xit denote the natural logarithm of the ratio of state $i$ per capita pollution relative to the national average in year $t$. A unit root implies that $x$ it is a nonstationary series, which can be described as follows

$$
x_{i t}=\mu_{i}+\beta_{i} x_{i t-1}+\varepsilon_{i t}, \varepsilon_{i t} \sim\left(0, \sigma^{2}\right) \text { and } E\left(\varepsilon_{i t} \varepsilon_{i t-j}\right)=0, j \neq 0 \text {, }
$$

where $\mu_{i}$ is a state-specific constant term or "drift," $\beta_{i}=1$, and $\varepsilon_{i t}$ is a white noise error term that is independent and identically distributed. A nonstationary $x_{i t}$ implies that any new shock $\left(\varepsilon_{i t}\right)$ to relative pollution in state $i$ will cause a permanent change with no tendency to converge back to a stable state-specific compensating differential, implying that per capita emission levels will diverge.

Perron (1989) demonstrates that failure to allow for an existing structural break leads to a bias against rejecting a false unit root null hypothesis. Perron (1989) proposes to allow for one known, or "exogenous," structural break in the augmented Dickey-Fuller (ADF, hereafter) unit root test. Following Perron (1989), Zivot and Andrews (1992) (ZA hereafter), and others, propose ADF-type tests to determine the break point "endogenously" from the data. The ZA test selects the break point where the $t$-statistic that tests the unit root null is minimized (i.e., the most negative) and, therefore, least favorable to the unit root hypothesis.

A potential problem common to the ZA and other ADF-type endogenous break unit root tests is that they derive their critical values while assuming no structural break(s) under the null. Nunes, Newbold, and Kuan (1997) and Lee and Strazicich (2001) show that this assumption leads to size distortions in the presence of a unit root with break. When utilizing ADF-type endogenous break tests, researchers might incorrectly conclude that a time series is trend-stationary when in fact the series is nonstationary with break(s). As such, a "spurious rejection" may result. To provide a remedy, we utilize the minimum Lagrange multiplier (LM) unit root tests of Lee and Strazicich $(2003,2004)$. These tests endogenously determine one or two structural breaks in level and trend. 
Implementation of the two-break minimum LM unit root test can be described as follows. According to theLM(score) principle, a unit root test statistic can be obtained from the following regression

$$
\Delta x_{t}=\delta^{\prime} \Delta Z_{t}+\phi \tilde{S}_{t-1}+\Sigma \gamma_{i} \Delta \tilde{S}_{t-i}+\varepsilon_{t},
$$

where $\tilde{S}_{t}$ is a de-trended series such that $\tilde{S}_{t}=x_{t}-\tilde{\Psi}_{x}-Z_{t} \tilde{\delta}, t=2, \ldots, T$; $\tilde{\delta}$ is a vector of coefficients in the regression of $\Delta x_{t}$ on $\Delta Z_{t}$ and $\tilde{\Psi}_{x}=x_{1}-Z_{1} \delta$, where $Z_{t}$ is defined below; $x_{1}$ and $Z_{1}$ are the first observations of $x_{t}$ and $Z_{t}$, respectively; $\Delta$ is the difference operator; and $\varepsilon_{t}$ is the contemporaneous error term and is assumed independent and identically distributed with zero mean and finite variance. To correct for serial correlation, $k$ number of lagged augmented terms $\Delta \tilde{S}_{t-1}, i=1, \ldots, k$, are included as necessary. ${ }^{11} Z_{t}$ is a vector of exogenous variables defined by the data-generating process. With two structural breaks in intercept and trend, $Z_{t}$ can be described as [1, $\left.t, D_{1 t}, D_{2 t}, D T_{1 t^{*}}{ }^{*} D T_{2 t^{*}}\right]^{\prime}$, where $D_{j t}=1$ for $t \geq T_{B j}+1, j=1,2$, and zero otherwise, $D T_{j t}{ }^{*}=t-T_{B j}$ for $t$ $\geq T_{B j}+1, j=1,2$, and zero otherwise, and $T_{B j}$ denotes the time period of the breaks. Note that the test regression (2) utilizes $\Delta Z_{t}$ instead of $Z_{t}$ so that $\Delta Z_{t}$ becomes [1, $\left.B_{1 t}, B_{2 t}, D_{1 t}, D_{2 t}\right]^{\prime}$, where $B_{j t}=\Delta D_{j t}$ and $D_{j t}=\Delta D T_{j t}{ }^{*}, j=1,2$. Under the unit root null hypothesis, $\phi=0$ in equation (2), and the test statistic can be defined as

$$
\tilde{\tau}=t-\text { statistic for the null hypothesis } \phi=0 .
$$

To determine endogenously the location of the two breaks $\left(\lambda_{j}=T_{B j} / T, j=\right.$ 1,2 ), the minimum LM unit root test finds the combination of breaks where the $t$-statistic testing the unit root null hypothesis is minimized. Since the critical values for the minimum LM test with level and trend breaks depend (somewhat) on the location of the breaks, we use critical values that correspond to $\lambda_{j}{ }^{12}$

After identifying two breaks in level and trend for each state, we examine the significance of each estimated break coefficient at the 10-percent level in an asymptotic normal distribution (i.e., critical value is 1.645). If two breaks are not significant, we reestimate our data using the one-break minimum LM unit root test of Lee and Strazicich (2004). If no break is significant at the 10-percent level in the one-break test, we utilize the conventional (no-break) ADF test.13

\section{Time Series Test for $\beta$-Convergence}

As previously noted, the conventional cross-section test for _-convergence has been criticized in the literature. In this paper, we utilize a time series test for_-convergence that was suggested in Carlino and Mills (1993). If per capita incomes are converging, then regression of the log relative income series on an intercept and trend should find opposite signs on their estimated coefficients. Intuitively, if a state has initial pollution emissions above the national mean then the intercept term of the log-relative series would be positive and the rate of growth of emissions should be negative in order for convergence to occur. Given that we identify structural breaks in level and trend for nearly all states, we wish to utilize this information in our time series tests for $\beta$-convergence. 
Our testing methodology can be described as follows. After performing unit root tests on the log of relative emissions as described above, we identify those states that reject the unit root null hypothesis (at the 10 percent level of significance). These time-series can be described as (trend) stationary around (in nearly all cases) one or two structural breaks in level and trend. Then, OLS regressions are performed on the log-relative emission series $(x t)$ for each of these states as follows

$$
x_{t}=\mu_{1} D 1_{t}+\mu_{2} D 2_{t}+\mu_{3} D 3_{t}+\gamma_{1} \text { TIME }_{t}+\gamma_{2} \text { TIME }_{t}+\gamma_{3} \text { TIME }_{t}+\varepsilon_{t},
$$

where $D 1_{t}, D 2_{t}$, and $D 3_{t}$, are intercept dummy variables and $T I M E 1_{t}, T I M E 2_{t}$, and $T I M E 3_{t}$ are linear time trends. $D 1_{t}=1$ if $t \leq T_{B 1}$, and zero otherwise; $D 2_{t}=1$ if $T_{B 1}<t \leq T_{B 2}$, and zero otherwise; and $D 3_{t}=1$ if $t>T_{B 2}$, and zero otherwise. TIME $1_{t}=t$ if $t \leq T_{B 1}$, and zero otherwise; TIME $2_{t}=t-T_{B 1}$ if $T_{B 1}<t \leq T_{B 2}$, and zero otherwise; and $T I M E 3_{t}=t-T_{B 2}$ if $t>T_{B 2}$, and zero otherwise. Thus, $\mu_{1}, \mu_{2}$, and $\mu_{3}$ denote whether the level of emissions in state $i$ are above (+) or below (-) the national average emissions prior to the first break, following the first break, and following the second break, respectively. In a similar manner, $\gamma_{1}, \gamma_{2}$, and $\gamma_{3}$ denote the growth rate of emissions relative to the mean over these same time periods, respectively.

Prior to 1970 we are interested in the time period following the final break to determine if emissions are converging, so we compare the signs of the estimated coefficients $\mu_{3}$ and $\gamma_{3}$. If the level of emissions in state i is converging to the mean, then $\mu_{3}$ and $\gamma_{3}$ should be of opposite sign. ${ }^{14}$ For states with only one significant break, equation (4) would be estimated without the $D 3_{t}$ and $T I M E 3_{t}$ terms and convergence would imply opposite signs on $\mu_{2}$ and $\gamma_{2}$ (i.e., opposite signs on level and trend). For states with no significant break, equation (4) would be estimated with only $D 1_{t}$ and $T I M E 1_{t}$ and convergence would imply opposite signs on $\mu_{1}$ and $\gamma_{1}$. For the later time period of 19701999 we initially focus on the period immediately after 1970 (i.e., $\mu_{1}$ and $\gamma_{1}$ ) to examine the short-run impact of federal controls. Since changing trends in spatial pollution patterns may take time, we will also examine the long-run effect on convergence by comparing signs on the intercept and trend following the final identified structural break (i.e., $\mu_{3}$ and $\gamma_{3}$ ). In addition, if the intercept term is significantly different from zero, but the trend is not, this would indicate evidence that emissions have conditionally converged to a state-specific constant differential. ${ }^{15}$ If neither the intercept nor the trend were significantly different from zero, this would indicate convergence is unconditional, or "absolute." In contrast, if the intercept and trend is the same sign then this would suggest that emissions are diverging. If the intercept term is not significantly different from zero, but the trend is, this would also suggest that emissions are diverging. ${ }^{16}$

\section{Empirical Results}

Prior to testing for convergence, it is interesting to examine our per capita emissions data to determine if the period around 1970 can be identified as a 
time of structural change. To perform this task, we estimate the minimum LM unit root test for each pollutant type using the raw data for the entire sample period of 1929-1999. The results are displayed in Table 2. The results indicate that the period surrounding 1970 does indeed contain a significant number of structural breaks in emissions. For each pollutant type, our results identify significant structural breaks in 21 (44 percent) of 48 states during the period around 1970 (1968-1976). We will now examine the time periods before and after 1970.

\section{Lack of Convergence in Most States under Local Control}

Estimation results are presented in Tables 3-6. We first examine the test results for stochastic convergence in Tables 3 and 4 . Regardless of the pollutant type and time period examined, the null of a unit root is rejected in nearly all cases (i.e., for SO2 85 percent of states reject the unit root null before 1970 and 92 percent after; for NOx 83 percent of states reject the unit root null before 1970 and 88 percent after). 17 These findings clearly reject the null that differences from the mean in per capita emission rates are nonstationary and, thus, provide support for stochastic convergence. As noted above, however, stochastic convergence is a necessary but not sufficient condition for convergence. To further our investigation, we next examine the results of testing the time-series notion of _-convergence in Tables 5 and 6 . These results are consistent for both types of pollutants. Prior to 1970 and the period of federal pollution control, the results for SO2 indicate that for about one-half of the states (52 percent) pollution emission rates were diverging. ForNOx, the results indicate that emissions are diverging for nearly half of the states (44 percent).

These results make sense in light of our discussion of interjurisdictional competition and the possibility of a regulatory race to the bottom. Industrial processes have historically been large emitters of SO2. Within this group of emitters are firms in the chemicals sector, primary metals industry, paper and allied sector, and many other types of manufacturers, all of which provide a tax base (jobs, etc.) annually to state and local economies. As discussed above, in their pursuit of firms and jobs, some policymakers may have attempted to attract polluting industry, inducing a divergence of emissions (see also Break, 1967, and Cumberland, 1980, who develop this "race to the bottom" argument more fully). Combining our empirical estimates with the fact that over this time period poorer states witnessed a much larger increase in their SO2 emission levels than wealthier states, we conclude that there is evidence which suggests some states have drifted away from one income/pollution path to another over time. This suggests the possibility that some states were setting increasingly lenient environmental policies to attract mobile capital (since in spite of converging incomes, emissions convergence is not predominate in the data). 
TABLE 2: Minimum LM Unit Root Tests of Per Capita Emissions

\begin{tabular}{|c|c|c|c|c|}
\hline \multirow[b]{2}{*}{ State } & \multicolumn{2}{|c|}{$\mathrm{SO}_{2}$} & \multicolumn{2}{|c|}{$\mathrm{NO}_{x}$} \\
\hline & 1929-1999 & Breaks & $1929-1999$ & Breaks \\
\hline$\overline{\text { Alabama }}$ & -5.13 & 1953,1970 & -3.51 & 1962 \\
\hline Arizona & $-6.27^{* *}$ & 1943,1976 & $-7.38^{* *+}$ & 1964,1981 \\
\hline Arkansas & -5.02 & 1956,1979 & -2.97 & 1943 \\
\hline California & $-6.12^{*+}$ & 1942,1950 & -4.31 & 1949,1976 \\
\hline Colorado & $-6.51^{* * *}$ & 1946,1961 & $-5.53^{*}$ & 1942,1974 \\
\hline Connecticut & $-5.37^{*}$ & 1956,1971 & $-4.71^{* *}$ & 1965 \\
\hline Delaware & -5.13 & 1956,1981 & -4.74 & 1977,1992 \\
\hline Florida & -4.55 & 1969,1980 & $-8.11^{* * *}$ & 1951,1969 \\
\hline Georgia & -5.11 & 1968,1984 & -4.09 & 1945,1980 \\
\hline Idaho & $-5.96^{* *}$ & 1944,1972 & $-7.91^{* * *}$ & 1939,1975 \\
\hline Illinois & $-7.51^{* * *}$ & 1951,1956 & -4.27 & 1939,1975 \\
\hline Indiana & $-5.55^{*}$ & 1951,1977 & -2.99 & 1977 \\
\hline Iowa & $-6.74^{* * *}$ & 1941,1952 & -5.12 & 1949,1978 \\
\hline Kansas & -5.08 & 1956,1973 & -4.99 & 1974,1991 \\
\hline Kentucky & $-5.97^{* *}$ & 1953,1970 & $-5.66^{*}$ & 1953,1970 \\
\hline Louisiana & $-7.67^{* * *}$ & 1974,1978 & $-5.71^{*}$ & 1940,1972 \\
\hline Maine & -4.82 & 1946,1961 & -5.13 & 1946,1965 \\
\hline Maryland & -4.78 & 1939,1950 & -5.00 & 1961,1978 \\
\hline Massachusetts & $-5.30^{*}$ & 1969,1977 & -5.18 & 1959,1980 \\
\hline Michigan & $-5.81^{* *}$ & 1963,1979 & -4.71 & 1962,1976 \\
\hline Minnesota & $-6.69^{* * *}$ & 1946,1966 & $-12.79^{* * *}$ & 1940,1950 \\
\hline Mississippi & -4.99 & 1947,1969 & -4.33 & 1948,1979 \\
\hline Missouri & -4.07 & 1971 & -3.87 & 1973 \\
\hline Montana & $-6.40^{* * *}$ & 1977 & $-5.05^{* *}$ & 1987 \\
\hline Nebraska & $-6.26^{* * *}$ & 1940,1952 & $-5.44^{*}$ & 1945,1981 \\
\hline Nevada & $-6.75^{*+*}$ & 1961,1979 & $-8.28^{*+*}$ & 1945,1962 \\
\hline New Hampshire & -4.18 & 1946 & $-5.81^{* *}$ & 1946,1966 \\
\hline New Jersey & $-5.89^{* *}$ & 1939,1950 & -2.78 & \\
\hline New Mexico & $-6.04^{* *}$ & 1964,1983 & $-5.58^{*}$ & 1975,1979 \\
\hline New York & -5.23 & 1965,1977 & $-5.60^{*}$ & 1969,1978 \\
\hline North Carolina & $-4.31^{*}$ & 1965 & -4.99 & 1966,1984 \\
\hline North Dakota & $-5.86^{* *}$ & 1974,1992 & $-7.25^{* * *}$ & 1967,1974 \\
\hline Ohio & $-6.97^{* * *}$ & 1977 & -5.25 & 1949,1976 \\
\hline Oklahoma & -4.57 & 1954,1976 & $-4.44^{*}$ & 1968 \\
\hline Oregon & $-5.71^{* *}$ & 1939,1955 & $-7.22^{*+*}$ & 1943,1952 \\
\hline Pennsylvania & $-5.65^{*}$ & 1966,1978 & -1.05 & \\
\hline Rhode Island & $-7.44^{* * *}$ & 1952,1971 & $-6.10^{* *}$ & 1951,1972 \\
\hline South Carolina & -4.42 & 1956,1977 & $-5.34^{*}$ & 1942,1968 \\
\hline South Dakota & -4.47 & 1964,1980 & $-4.84^{* * *}$ & \\
\hline Tennessee & $-5.77^{* *}$ & 1957,1970 & -4.58 & 1955,1980 \\
\hline Texas & -4.44 & 1948,1974 & $-5.84^{* *}$ & 1940,1969 \\
\hline Utah & $-6.26^{* *}$ & 1950,1971 & $-5.33^{*}$ & 1948,1970 \\
\hline Vermont & $-5.34^{*}$ & 1940,1951 & $-5.09^{* * *}$ & 1947 \\
\hline Virginia & -4.70 & 1941,1952 & $-4.47^{*}$ & 1965 \\
\hline Washington & -4.28 & 1975,1980 & $-4.68^{* *}$ & 1973 \\
\hline West Virginia & $-4.35^{*}$ & 1969 & $-5.63^{*}$ & 1965,1973 \\
\hline Wisconsin & $-6.86^{* * *}$ & 1946,1967 & -3.57 & 1964 \\
\hline Wyoming & $-6.87^{* * *}$ & 1970,1988 & $-7.07^{* * *}$ & 1966,1980 \\
\hline
\end{tabular}

Notes: The dependent variable is the level of per capita emissions. Test statistic is the t-statistic that tests the null hypothesis of a unit root. All unit root tests include an intercept and trend. Breaks denote the break years that were identified by the one- or two-break minimum LM unit root test. A blank space denotes no breaks were significant at the 10 percent level. In the case of no significant breaks, the results shown are those obtained using the conventional (no break) ADF test. ${ }^{* *+, * *}$, and ${ }^{*}$ denote significance at the 1 percent, 5 percent, and 10 percent levels, respectively. Critical values for the one- and two-break minimum LM test come from Lee and Strazicich (2003, 2004). Critical values for the (no-break) ADF test are from MacKinnon (1991). 
TABLE 3: Minimum LM Unit Root Tests for Stochastic Convergence of $\mathrm{SO}_{2}$

\begin{tabular}{|c|c|c|c|c|}
\hline State & $1929-1969$ & Breaks & $1970-1999$ & Breaks \\
\hline Alabama & $-9.76^{*+*}$ & 1950,1957 & $-6.41^{*+}$ & 1981,1985 \\
\hline Arizona & $-8.89^{*+*}$ & 1941,1950 & $-7.17^{\text {+** }}$ & 1987,1991 \\
\hline Arkansas & $-5.79^{* *}$ & 1948,1957 & $-5.06^{4+4}$ & 1987 \\
\hline California & $-5.13^{*+*}$ & 1949 & $-7.18^{4+4}$ & 1984,1994 \\
\hline Colorado & -5.06 & 1950,1960 & $-7.79^{4+4}$ & 1983,1993 \\
\hline Connecticut & $-8.76^{*+*}$ & 1943,1958 & $-5.85^{* *}$ & 1990,1993 \\
\hline Delaware & $-7.93^{*+*}$ & 1945,1957 & $-9.68^{* 4 *}$ & 1980,1993 \\
\hline Florida & $-9.77^{*+*}$ & 1940,1955 & $-5.71^{* *}$ & 1981,1989 \\
\hline Georgia & $-5.87^{* *}$ & 1950,1965 & $-6.47^{* 4 *}$ & 1987,1996 \\
\hline Idaho & $-6.94^{* * *}$ & 1947,1960 & $-7.40^{4 * 4}$ & 1982,1986 \\
\hline Illinois & $-5.66^{*}$ & 1941,1952 & $-6.07^{4+}$ & 1988,1996 \\
\hline Indiana & $-7.38^{* * *}$ & 1941,1948 & $-5.45^{*}$ & 1983,1987 \\
\hline Iowa & $-6.72^{++4}$ & 1951,1960 & $-8.86^{+4 *}$ & 1981,1986 \\
\hline Kansas & $-7.97^{* * *}$ & 1951,1955 & $-5.98^{4 *}$ & 1982,1993 \\
\hline Kentucky & $-6.99^{* * *}$ & 1950,1958 & $-5.39^{*}$ & 1986,1991 \\
\hline Louisiana & $-5.92^{* * *}$ & 1957 & $-10.02^{*+*}$ & 1984,1988 \\
\hline Maine & $-5.39^{*}$ & 1941,1949 & $-12.34^{* * *}$ & 1981,1993 \\
\hline Maryland & -3.92 & 1939,1953 & $-6.48^{+4 *}$ & 1985,1994 \\
\hline Massachusetts & $-9.88^{*+*}$ & 1944,1956 & $-7.96^{+* 4}$ & 1980,1990 \\
\hline Michigan & $-5.96^{* *}$ & 1944,1964 & $-6.49^{*+*}$ & 1980,1994 \\
\hline Minnesota & $-4.62^{* *}$ & 1953 & $-6.87^{4+4}$ & 1983,1993 \\
\hline Mississippi & $-5.57^{*}$ & 1946,1955 & $-6.74^{4+4}$ & 1980,1986 \\
\hline Missouri & -4.63 & 1947,1961 & $-11.66^{*+*}$ & 1981,1991 \\
\hline Montana & $-9.34^{*+*}$ & 1942,1955 & $-11.87^{*+*}$ & 1981,1995 \\
\hline Nebraska & $-6.93^{*+*}$ & 1951,1955 & $-14.61^{*+*}$ & 1980,1993 \\
\hline Nevada & $-5.64^{*}$ & 1944,1950 & -4.83 & 1980,1986 \\
\hline New Hampshire & $-7.53^{*+*}$ & 1947,1957 & $-10.32^{*+*}$ & 1982,1993 \\
\hline New Jersey & -4.16 & 1948 & $-8.20^{* * *}$ & 1988,1993 \\
\hline New Mexico & $-6.71^{* * *}$ & 1951,1960 & -4.85 & 1982,1987 \\
\hline New York & $-5.98^{* *}$ & 1951,1960 & $-5.52^{+4+}$ & 1984 \\
\hline North Carolina & $-6.72^{*+*}$ & 1943,1956 & $-7.64^{+* 4}$ & 1985,1994 \\
\hline North Dakota & $-6.72^{* * *}$ & 1945,1949 & $-10.89^{* * *}$ & 1980,1993 \\
\hline Ohio & $-6.52^{* * *}$ & 1951,1959 & $-7.21^{* * *}$ & 1988,1994 \\
\hline Oklahoma & $-5.86^{* *}$ & 1956,1960 & $-6.46^{*+*}$ & 1981,1993 \\
\hline Oregon & $-5.32^{*}$ & 1956,1965 & $-5.38^{*}$ & 1983,1989 \\
\hline Pennsylvania & $-5.35^{*}$ & 1949,1962 & $-5.98^{*+*}$ & 1988,1994 \\
\hline Rhode Island & -4.58 & 1942,1960 & $-9.15^{4+*}$ & 1982,1993 \\
\hline South Carolina & -4.62 & 1939,1952 & -4.48 & 1980,1991 \\
\hline South Dakota & $-8.18^{* * *}$ & 1943,1964 & $-8.15^{4 * 4}$ & 1986,1992 \\
\hline Tennessee & $-6.16^{* *}$ & 1947,1958 & $-7.72^{+* \psi}$ & 1987,1992 \\
\hline Texas & $-6.28^{+* t}$ & 1948 & $-5.48^{\circ}$ & 1983,1992 \\
\hline Utah & $-8.29^{*+4}$ & 1946,1956 & $-6.07^{* 4}$ & 1982,1996 \\
\hline Vermont & $-10.37^{* * *}$ & 1947,1954 & $-22.70^{4 * 4}$ & 1985,1993 \\
\hline Virginia & -4.78 & 1943,1959 & $-8.20^{*+*}$ & 1981,1993 \\
\hline Washington & $-5.52^{* *}$ & 1944,1952 & $-11.56^{*+4}$ & 1984,1990 \\
\hline West Virginia & $-7.37^{*+*}$ & 1947,1955 & -4.72 & 1983,1994 \\
\hline Wisconsin & $-7.24^{\text {t+t }}$ & 1947,1956 & $-7.60^{4 *+}$ & 1990,1993 \\
\hline Wyoming & $-5.35^{*+*}$ & 1962 & $-6.42^{4 * 4}$ & 1981,1993 \\
\hline
\end{tabular}

Notes: The dependent variable is the natural logarithm of the ratio of per capita $\mathrm{SO}_{2}$ emissions for state $\mathrm{i}$ in year $t$ divided by the average per capita $\mathrm{SO}_{2}$ emissions of 48 states in year $t$. Test statistic is the $t$-statistic that tests the null hypothesis of a unit root. Rejection of the null hypothesis supports stochastic convergence. All unit root tests include an intercept and trend. Breaks denote the break years that were identified by the one- or two-break minimum LM unit root test. A blank space denotes no breaks were significant at the 10 percent level. In the case of no significant breaks, the results shown are those obtained using the conventional (no break) ADF test. ${ }^{* *+, *+}$, and ${ }^{*}$ denote significance at the 1 percent, 5 percent, and 10 percent levels, respectively. Critical values for the one- and two-break minimum LM test come from Lee and Strazicich (2003, 2004). Critical values for the (no-break) ADF test are from MacKinnon (1991). 
TABLE 4: Minimum LM Unit Root Tests for Stochastic Convergence of $\mathrm{NO}_{x}$

\begin{tabular}{|c|c|c|c|c|}
\hline State & $1929-1969$ & Breaks & $1970-1999$ & Breaks \\
\hline Alabama & $-6.71^{* * *}$ & 1943,1955 & -3.82 & 1990 \\
\hline Arizona & $-10.22^{* * *}$ & 1941,1951 & $-11.58^{* * *}$ & 1984,1991 \\
\hline Arkansas & $-7.52^{* * *}$ & 1941,1953 & $-9.88^{* * *}$ & 1991 \\
\hline California & $-8.26^{* * *}$ & 1958 & $-6.01^{* *}$ & 1985,1994 \\
\hline Colorado & -3.87 & 1940 & -5.22 & 1981,1994 \\
\hline Connecticut & $-6.70^{* * *}$ & 1941,1947 & $-9.70^{*+*}$ & 1984,1987 \\
\hline Delaware & $-7.11^{* * *}$ & 1943,1955 & $-15.40^{* * *}$ & 1980,1993 \\
\hline Florida & $-8.07^{* * *}$ & 1945,1952 & $-6.31^{* *}$ & 1982,1989 \\
\hline Georgia & $-5.50^{* *}$ & 1941,1950 & $-6.84^{*+*}$ & 1983,1995 \\
\hline Idaho & $-5.95^{* *}$ & 1941,1945 & $-6.43^{* *}$ & 1982,1987 \\
\hline Illinois & $-5.77^{* *}$ & 1948,1955 & $-7.60^{*+*}$ & 1981,1991 \\
\hline Indiana & $-5.86^{* *}$ & 1940,1946 & $-7.06^{*+*}$ & 1985 \\
\hline Iowa & $-6.18^{* *}$ & 1947,1950 & $-7.80^{*+4}$ & 1980,1993 \\
\hline Kansas & $-5.80^{* *}$ & 1941,1956 & $-6.09^{* *}$ & 1986,1991 \\
\hline Kentucky & $-6.14^{* * *}$ & 1952 & $-10.01^{* * *}$ & 1991,1996 \\
\hline Louisiana & $-7.89^{* * *}$ & 1942,1957 & $-11.55^{* * *}$ & 1982,1993 \\
\hline Maine & -4.89 & 1941,1955 & $-5.64^{*}$ & 1984,1987 \\
\hline Maryland & -4.08 & 1946 & $-5.97^{* *}$ & 1984,1993 \\
\hline Massachusetts & $-4.80^{* * *}$ & & -5.12 & 1983,1987 \\
\hline Michigan & $-5.01^{* * *}$ & & $-7.92^{* * *}$ & 1983,1989 \\
\hline Minnesota & $-14.59^{* * *}$ & 1940,1949 & $-9.06^{*+*}$ & 1982,1993 \\
\hline Mississippi & -5.25 & 1941,1951 & $-4.73^{*+}$ & 1983 \\
\hline Missouri & -4.57 & 1948,1963 & $-9.68^{t+*}$ & 1980,1993 \\
\hline Montana & $-7.24^{* * *}$ & 1941,1954 & $-13.63^{* * *}$ & 1987,1996 \\
\hline Nebraska & $-4.89^{* *}$ & 1949 & $-9.93^{*+*}$ & 1988,1993 \\
\hline Nevada & $-7.82^{* * *}$ & 1945,1959 & $-6.68^{*+4}$ & 1984,1994 \\
\hline New Hampshire & $-5.23^{*+*}$ & 1945 & $-5.92^{* *}$ & 1980,1984 \\
\hline New Jersey & $-4.89^{* *}$ & 1947 & $-11.27^{* * *}$ & 1993,1996 \\
\hline New Mexico & $-\mathbf{5 . 9 3 * *}$ & 1946,1956 & $-6.97^{*+*}$ & 1980,1990 \\
\hline New York & $-8.60^{* * *}$ & 1947,1957 & $-6.39^{*+}$ & 1982,1995 \\
\hline North Carolina & -4.93 & 1947,1955 & $-6.66^{* * *}$ & 1986,1995 \\
\hline North Dakota & -2.93 & & $-8.74^{*+*}$ & 1982,1993 \\
\hline Ohio & $-5.73^{* * *}$ & 1948 & $-6.02^{* *}$ & 1981,1993 \\
\hline Oklahoma & -2.85 & & $-7.17^{*+*}$ & 1987,1994 \\
\hline Oregon & $-5.00^{* *}$ & 1949 & -4.44 & 1980,1993 \\
\hline Pennsylvania & $-6.90^{* * *}$ & 1945,1957 & $-6.17^{* *}$ & 1982,1989 \\
\hline Rhode Island & $-6.07^{* *}$ & 1947,1958 & $-5.68^{*+*}$ & 1981 \\
\hline South Carolina & $-9.31^{* * *}$ & 1939,1947 & $-6.79^{* *+}$ & 1986,1993 \\
\hline South Dakota & $-8.06^{* * *}$ & 1940,1961 & $-7.33^{*+*}$ & 1988,1993 \\
\hline Tennessee & $-6.51^{* * *}$ & 1944,1952 & -5.17 & 1981,1993 \\
\hline Texas & $-4.38^{*+*}$ & & $-11.76^{* * *}$ & 1982,1993 \\
\hline Utah & $-8.90^{* * *}$ & 1946,1957 & $-7.43^{*+*}$ & 1982,1994 \\
\hline Vermont & $-9.86^{* * *}$ & 1947,1959 & $-10.95^{* * *}$ & 1982,1993 \\
\hline Virginia & $-6.54^{* * *}$ & 1944,1949 & $-10.42^{* * *}$ & 1981,1993 \\
\hline Washington & $-7.69^{* * *}$ & 1947,1954 & $-5.33^{*}$ & 1984,1993 \\
\hline West Virginia & $-6.63^{*+*}$ & 1942 & $-5.52^{*}$ & 1989,1995 \\
\hline Wisconsin & $-7.48^{* * *}$ & 1942,1950 & $-8.64^{*+4}$ & 1986,1990 \\
\hline Wyoming & $-6.38^{* *}$ & 1941,1958 & -4.78 & 1980,1994 \\
\hline
\end{tabular}

Notes: The dependent variable is the natural logarithm of the ratio of per capita $\mathrm{NO}_{\mathbf{x}}$ emissions for state $i$ in year $t$ divided by the average per capita $\mathrm{NO}_{x}$ emissions of 48 states in year $t$. Test statistic is the $t$-statistic that tests the null hypothesis of a unit root. Rejection of the null hypothesis supports stochastic convergence. All unit root tests include an intercept and trend. Breaks denote the break years that were identified by the one- or two-break minimum LM unit root test. A blank space denotes no breaks were significant at the 10 percent level. In the case of no significant breaks, the results shown are those obtained using the conventional (no break) ADF test. ${ }^{* *+, * *}$, and ${ }^{*}$ denote significance at the 1 percent, 5 percent, and 10 percent levels, respectively. Critical values for the one- and two-break minimum LM test come from Lee and Strazicich (2003, 2004). Critical values for the (no-break) ADF test are from MacKinnon (1991). 
TABLE 5: Summary of Time-Series Tests for Convergence of $\mathrm{SO}_{2}$ Emissions

\begin{tabular}{|c|c|c|c|c|c|}
\hline State & $\begin{array}{c}\text { Before } \\
1970\end{array}$ & $\begin{array}{c}\text { After } 1970 \\
\text { short-run long-run }\end{array}$ & State & $\begin{array}{c}\text { Before } \\
1970\end{array}$ & $\begin{array}{c}\text { After } 1970 \\
\text { short-run long-run }\end{array}$ \\
\hline Alabama & $\mathrm{d}$ & C, D & Nebraska & $\mathrm{c}$ & $\mathrm{C}, \mathrm{c}$ \\
\hline Arizona & $\mathrm{C}$ & $\mathrm{C}, \mathrm{d}$ & Nevada & $\mathrm{C}$ & $\mathrm{U}$ \\
\hline Arkansas & $\mathrm{D}$ & $\mathrm{C}, \mathrm{C}$ & New Hampshire & $\mathrm{C}$ & $\mathrm{c}, \mathrm{d}$ \\
\hline California & D & $\mathrm{D}, \mathrm{c}$ & New Jersey & $\mathrm{U}$ & $\mathrm{D}, \mathrm{c}$ \\
\hline Colorado & $\mathrm{U}$ & $\mathrm{C}, \mathrm{c}$ & New Mexico & $\mathrm{D}$ & $\mathrm{U}$ \\
\hline Connecticut & $\mathrm{D}$ & $\mathrm{c}, \mathrm{c}$ & New York & $\mathrm{D}$ & $\mathrm{C}, \mathrm{C}$ \\
\hline Delaware & $\mathrm{C}$ & $\mathrm{A}, \mathrm{C}$ & North Carolina & $\mathrm{C}$ & $\mathrm{C}, \mathrm{d}$ \\
\hline Florida & $\mathrm{c}$ & $\mathrm{c}, \mathrm{C}$ & North Dakota & D & C, D \\
\hline Georgia & $\mathrm{c}$ & $\mathrm{C}, \mathrm{A}$ & Ohio & $\mathrm{c}$ & $\mathrm{D}, \mathrm{c}$ \\
\hline Idaho & $\mathrm{C}$ & $\mathrm{c}, \mathrm{c}$ & Oklahoma & $\mathrm{D}$ & $\mathrm{C}, \mathrm{c}$ \\
\hline Illinois & $\mathrm{C}$ & $\mathrm{C}, \mathrm{c}$ & Oregon & c & $\mathrm{c}, \mathrm{C}$ \\
\hline Indiana & $\mathrm{D}$ & $\mathrm{D}, \mathrm{C}$ & Pennsylvania & $\mathrm{D}$ & $\mathrm{D}, \mathrm{c}$ \\
\hline Iowa & $\mathrm{C}$ & $\mathrm{C}, \mathrm{d}$ & Rhode Island & $\mathrm{U}$ & $\mathrm{c}, \mathrm{c}$ \\
\hline Kansas & $\mathrm{D}$ & $\mathrm{C}, \mathrm{C}$ & South Carolina & $\mathrm{U}$ & $\mathrm{U}$ \\
\hline Kentucky & $\mathrm{D}$ & $\mathrm{C}, \mathrm{C}$ & South Dakota & $\mathrm{C}$ & $\mathrm{c}, \mathrm{C}$ \\
\hline Louisiana & $\mathrm{D}$ & $\mathrm{C}, \mathrm{A}$ & Tennessee & $\mathrm{c}$ & $\mathrm{c}, \mathrm{C}$ \\
\hline Maine & $\mathrm{C}$ & $\mathrm{c}, \mathrm{c}$ & Texas & $\mathrm{D}$ & C, D \\
\hline Maryland & $\mathrm{U}$ & $\mathrm{C}, \mathrm{A}$ & Utah & $\mathrm{C}$ & $\mathrm{C}, \mathrm{d}$ \\
\hline Massachusetts & $\mathrm{c}$ & $\mathrm{C}, \mathrm{c}$ & Vermont & $\mathrm{c}$ & $\mathrm{c}, \mathrm{C}$ \\
\hline Michigan & $\mathrm{c}$ & $\mathrm{C}, \mathrm{c}$ & Virginia & $\mathrm{U}$ & c, A \\
\hline Minnesota & $\mathrm{C}$ & $\mathrm{D}, \mathrm{C}$ & Washington & $\mathrm{D}$ & $\mathrm{C}, \mathrm{c}$ \\
\hline Mississippi & $\mathrm{c}$ & $\mathrm{C}, \mathrm{C}$ & West Virginia & D & $\mathrm{U}$ \\
\hline Missouri & $\mathrm{U}$ & $\mathrm{D}, \mathrm{C}$ & Wisconsin & D & $\mathrm{C}, \mathrm{C}$ \\
\hline Montana & $\mathrm{C}$ & $\mathrm{C}, \mathrm{A}$ & Wyoming & D & $\mathrm{D}, \mathrm{D}$ \\
\hline
\end{tabular}

Notes: To be considered as converging, the time-series of log-relative $\mathrm{SO}_{2}$ emissions for state i must satisfy the following criteria. First, the log-relative time-series must reject the null hypothesis of a unit root, implying that emissions are not diverging. Next, for those states that reject the unit root null hypothesis (at the 10 percent level of significance), an OLS regression on the intercept(s) and trend(s) was performed that includes structural breaks identified with the minimum LM unit root test. Finally, the coefficients on the intercept and trend in the time period before and after 1969, respectively, must indicate that emissions are converging or have already converged. The short run describes the initial intercept and trend after 1969, while the long run describes the final intercept and trend. The notation is described as follows:

${ }^{\prime \prime} \mathrm{C}$ " denotes point estimates consistent with convergence that are each statistically significant at the 10 percent level (i.e., coefficient of intercept and trend are of opposite signs).

" $\mathrm{c}$ " denotes point estimates that suggest conditional convergence has occurred (i.e., the intercept is statistically significant at the 10 percent level and the trend is not).

"A" denotes point estimates very small in magnitude and statistically insignificant, which combined with being stationary, suggests that absolute convergence has occurred.

" $\mathrm{D}$ " denotes point estimates consistent with divergence that are each statistically significant at the 10 percent level (i.e., coefficient of intercept and trend have the same sign).

" $\mathrm{d}$ " denotes point estimates consistent with divergence, wherein the trend is statistically significant at the 10 percent level and the intercept is not.

" $U$ " denotes unit root, which implies that the null hypothesis of divergence cannot be rejected.

Therefore, C, c, and A denote evidence of convergence and D, d, and U imply that divergence cannot be rejected. 
TABLE 6: Summary of Time-Series Tests for Convergence of $\mathrm{NO}_{\mathrm{x}}$ Emissions

\begin{tabular}{|c|c|c|c|c|c|}
\hline State & $\begin{array}{c}\text { Before } \\
1970\end{array}$ & $\begin{array}{c}\text { After } 1970 \\
\text { short-run long-run }\end{array}$ & State & $\begin{array}{c}\text { Before } \\
1970\end{array}$ & $\begin{array}{c}\text { After } 1970 \\
\text { short-run long-run }\end{array}$ \\
\hline Alabama & d & $\mathrm{U}$ & Nebraska & $\mathrm{C}$ & d, D \\
\hline Arizona & d & $\mathrm{d}, \mathrm{A}$ & Nevada & $\mathrm{A}$ & $\mathrm{c}, \mathrm{A}$ \\
\hline Arkansas & $\mathrm{C}$ & $\mathrm{C}, \mathrm{C}$ & New Hampshire & $\mathrm{c}$ & $\mathrm{D}, \mathrm{C}$ \\
\hline California & $\mathrm{c}$ & $\mathrm{D}, \mathrm{c}$ & New Jersey & $\mathrm{d}$ & $\mathrm{D}, \mathrm{c}$ \\
\hline Colorado & $\mathrm{U}$ & $\mathrm{U}$ & New Mexico & $\mathrm{D}$ & $\mathrm{C}, \mathrm{c}$ \\
\hline Connecticut & c & $\mathrm{D}, \mathrm{c}$ & New York & $\mathrm{c}$ & $\mathrm{c}, \mathrm{c}$ \\
\hline Delaware & A & $\mathrm{A}, \mathrm{C}$ & North Carolina & $\mathrm{U}$ & d, $C$ \\
\hline Florida & d & $\mathrm{c}, \mathrm{c}$ & North Dakota & $\mathrm{U}$ & $\mathrm{D}, \mathrm{c}$ \\
\hline Georgia & $\mathrm{c}$ & $\mathrm{C}, \mathrm{A}$ & Ohio & $\mathrm{c}$ & $\mathrm{c}, \mathrm{c}$ \\
\hline Idaho & $\mathrm{C}$ & $\mathrm{C}, \mathrm{A}$ & Oklahoma & $\mathrm{U}$ & $\mathrm{c}, \mathrm{C}$ \\
\hline Illinois & $\mathrm{C}$ & d, C & Oregon & $\mathrm{d}$ & $\mathrm{U}$ \\
\hline Indiana & $\mathrm{D}$ & $\mathrm{C}, \mathrm{C}$ & Pennsylvania & $\mathrm{A}$ & $\mathrm{A}, \mathrm{c}$ \\
\hline Iowa & A & A, D & Rhode Island & $\mathrm{D}$ & $\mathrm{C}, \mathrm{C}$ \\
\hline Kansas & $\mathrm{c}$ & $\mathrm{D}, \mathrm{c}$ & South Carolina & $\mathrm{C}$ & $\mathrm{C}, \mathrm{d}$ \\
\hline Kentucky & d & $\mathrm{D}, \mathrm{c}$ & South Dakota & $\mathrm{C}$ & $\mathrm{A}, \mathrm{d}$ \\
\hline Louisiana & $\mathrm{c}$ & $\mathrm{C}, \mathrm{c}$ & Tennessee & $\mathrm{c}$ & $\mathrm{U}$ \\
\hline Maine & $\mathrm{U}$ & $\mathrm{c}, \mathrm{C}$ & Texas & $\mathrm{D}$ & $\mathrm{C}, \mathrm{C}$ \\
\hline Maryland & $\mathrm{U}$ & $\mathrm{c}, \mathrm{c}$ & Utah & $\mathrm{C}$ & $\mathrm{C}, \mathrm{c}$ \\
\hline Massachusetts & $\mathrm{D}$ & $\mathrm{U}$ & Vermont & $\mathrm{c}$ & $\mathrm{c}, \mathrm{C}$ \\
\hline Michigan & $\mathrm{C}$ & $\mathrm{D}, \mathrm{c}$ & Virginia & $\mathrm{C}$ & $\mathrm{D}, \mathrm{c}$ \\
\hline Minnesota & $\mathrm{c}$ & C, d & Washington & $\mathrm{c}$ & $\mathrm{C}, \mathrm{c}$ \\
\hline Mississippi & $\mathrm{U}$ & $\mathrm{C}, \mathrm{C}$ & West Virginia & $\mathrm{D}$ & $\mathrm{D}, \mathrm{c}$ \\
\hline Missouri & $\mathrm{U}$ & $\mathrm{d}, \mathrm{c}$ & Wisconsin & $\mathrm{C}$ & $\mathrm{C}, \mathrm{A}$ \\
\hline Montana & $\mathrm{C}$ & $\mathrm{D}, \mathrm{D}$ & Wyoming & $\mathrm{D}$ & $\mathrm{U}$ \\
\hline
\end{tabular}

Notes: To be considered as converging, the time-series of log-relative $\mathrm{NO}_{x}$ emissions for state $i$ must satisfy the following criteria. First, the log-relative time-series must reject the null hypothesis of a unit root, implying that emissions are not diverging. Next, for those states that reject the unit root null hypothesis (at the 10 percent level of significance), an OLS regression on the intercept(s) and trend(s) was performed that includes structural breaks identified with the minimum LM unit root test. Finally, the coefficients on the intercept and trend in the time period before and after 1969, respectively, must indicate that emissions are converging or have already converged. The short run describes the initial intercept and trend after 1969, while the long run describes the final intercept and trend. The notation is described as follows:

" $\mathrm{C}$ " denotes point estimates consistent with convergence that are each statistically significant at the 10 percent level (i.e., coefficient of intercept and trend are of opposite signs).

"c" denotes point estimates that suggest conditional convergence has occurred (i.e., the intercept is statistically significant at the 10 percent level and the trend is not).

" $\mathrm{A}$ " denotes point estimates very small in magnitude and statistically insignificant, which combined with being stationary, suggests that absolute convergence has occurred.

" $\mathrm{D}$ " denotes point estimates consistent with divergence that are each statistically significant at the 10 percent level (i.e., coefficient of intercept and trend have the same sign).

" $\mathrm{d}$ " denotes point estimates consistent with divergence, wherein the trend is statistically significant at the 10 percent level and the intercept is not.

" $U$ " denotes unit root, which implies that the null hypothesis of divergence cannot be rejected.

Therefore, C, c, and A denote evidence of convergence and D, d, and U imply that divergence cannot be rejected. 


\section{Convergence Followed the Environmental Movement}

Examining data from 1970 to 1999 , a time span when the federal government played a much stronger role in air pollution regulation via the Clean Air Act Amendments of 1970, we find different results. During this later period of more federal pollution control, we see stronger evidence that emissions are converging. The post-1970 results are displayed in Tables 5 and 6.We first examine the (short-run) impact on convergence in the period immediately following the imposition of federal controls. For SO2, in contrast to the earlier time period, pollution emissions are now clearly converging for most states (75 percent). For $\mathrm{NO}_{\mathrm{x}}$, the evidence is essentially unchanged as compared to the earlier period, with convergence occurring in about one-half (54 percent) of the states. Given that adjustment of pollution patterns to federal controls may take time, we next examine the long-run evidence of convergence after 1970. In the long run, the evidence for convergence of SO2 emissions is essentially unchanged (73 percent of states are found to have converged), but the evidence for convergence of $\mathrm{NO}_{\mathrm{x}}$ gets considerably stronger: 75 percent of states are now found to be converging (up from 54 percent).

These empirical findings suggest that an added silver lining followed the centralization of environmental policies in the U.S.: since many types of pollutants are believed to have threshold effects (e.g., a minimum level that can be emitted before serious harm), pollutants having an equivalent conditional mean across space may decrease the chance of crossing important thresholds. In addition, from a social welfare perspective, this finding is of note because policymakers may be interested in a more equal distribution of public "bads," such as pollution.18

\section{CONCLUSIONS}

Empirical studies examining the temporal path of relative incomes have recently proliferated, with the bulk of evidence suggesting that the conditional convergence prediction of Solow's (1956) neoclassical growth model adequately describes the growth process. At the same time, a large literature has developed that finds a link between income and pollution levels through time (e.g., Grossman and Krueger, 1995). While these findings are important in isolation, combining their key features yields potentially significant new insights. In this study we link these two literatures by examining the spatial and temporal distribution of pollution. Since key aspects of any public policy are efficiency and distributional consequences, our results may also have policy relevance.

Using state-level data on sulfur dioxide and nitrogen oxide emissions from 1929 to 1999, we find that during the years of state pollution control, for about one-half of the states, emissions did not converge. Interestingly, lower state emission levels and stronger evidence of emissions convergence occurred in the era of federal controls. These findings are consonant with the notion that without a nationwide pollution control standard certain regions or groups of people may not enjoy a similar quality of air and water as individuals in other regions. 


\section{NOTES}

1. In the U.S., responsibility of regulating polluters rested almost exclusively with the states until 1970 (Portney, 1990). The federal government began to take a more active role in environmental regulation during the Nixon years when the President declared himself an environmentalist and proclaimed the onset of the "environmental decade" on January 1, 1970. President Nixon subsequently passed the most important air pollution control bill in history-the Clean Air Act Amendments of 1970 — and created the EPA by executive order in 1970 to implement the Amendments. This regime change affords us the opportunity to examine pollution paths in the pre- and post-centralization eras to make inference regarding the relationship between institutional arrangements and the spatial distribution of pollutants.

2. The causal mechanism for this EKC has been the subject of some debate. Some analysts have pointed to political economy linkages (such as based on the Coase theorem), and others have emphasized the technical relationship between consumption and abatement (e.g., Andreoni and Levinson, 2001), or changes in this relationship over time due to technical change (e.g., Stokey,1998). Brock and Taylor (2004) present a model wherein technical change in abatement is proportional to the average abatement intensity in the economy (i.e., individual abatement efforts provide knowledge spillovers to others in the economy).

3. One oft-cited disadvantage of local regulatory decision making is that spill-overs are not internalized, and therefore too much pollution is a general outcome when localities have regulatory authority. Another disadvantage of local pollution control relates to the potentially adverse consequences of interjurisdictional competition (Wilson (1996) and below).

4. Of course, given the mobility opportunities in the U.S., individuals will migrate in response to spatial arbitrage opportunities, leading to the marginal person being indifferent to locations at any point in time.

5. Policymakers may be tempted to resort to lax environmental policies in an effort to attract mobile capital (as opposed to, for example, more efficient capital subsidies) if environmental policy formulation is less transparent to voters ("optimal obfuscation").

6. For an overview of reasons why competing local jurisdictions may produce distorted outcomes, refer to surveys by Wellisch (2000) and Wilson (1996, 1999). Oates (2002) concludes that the theoretical literature is inconclusive on whether races to the bottom or optimal regulation (i.e., convergence of pollution in light of the evidence above) will occur.

7. This type of convergence has been termed conditional convergence by Mankiw, Romer, and Weil (1992). Conditional convergence occurs if state-level emissions converge to a (statespecific) constant differential. This definition appears appropriate given that assimilative capacities, preferences, etc., differ across states.

8. Stochastic convergence not necessarily implying convergence is further apparent from the possibility that the log ratio series may be trend-stationary along a trend that diverges from the national mean.

9. For examples of papers that criticize the cross-section test of _-convergence see Friedman, 1992; Quah, 1993; Evans and Karras, 1996a. 
10. For a detailed discussion of the methods used to estimate our emissions data please see the document "National Air Pollutant Emission Trends, Procedures Document, 1900-1996" (U.S. Environmental Protection Agency, 1998). Various procedure reports are available on the web at "http://www.epa.gov/ttn/chief/trends/index.html." It should be noted that the emissions data employed in our empirical tests are primarily estimated from actual fuel consumption and emissions, and not from state or national aggregate income, industrial production, or GDP. We thank Roy Huntley and the staff of the EPA for helpful discussions regarding the emissions data.

11. To determine the optimal number of $k$ lagged augmentation terms that correct for serial correlation in equation (2) we follow the "general to specific" procedure suggested by Perron (1989). At each combination of two breaks in the time interval [.1T, .9T] (to eliminate end points), where $T$ is the sample size, we begin with a maximum number of lagged firstdifferenced terms $k=8$ and examine the last term to see if it is significantly different from zero at the 10-percent level in an asymptotic normal distribution (critical value is 1.645). If insignificant, the maximum lagged term is dropped and the model is reestimated with $k=7$ terms and so on, until either the maximum term is found or $k=0$, at which point the procedure stops. This technique has been shown to perform well as compared to other data dependent procedures to select the number of lagged augmented terms (e.g., Ng and Perron, 1995).

12. Although the critical values for the minimum LM test with intercept and trend breaks depend (somewhat) on the location of the break(s), the test remains free of size distortions and spurious rejections in the presence of a unit root with break(s).

13. Gauss codes for the one- and two-break minimum LM unit root test are available online at http://www.cba.ua.edu/ jlee/gauss.

14. See Tomljanovich and Vogelsang (2002) for a similar application of the time-series notion of $\beta$-convergence applied to per capita incomes of the U.S. regions.

15. Tomljanovich and Vogelsang (2002) do not consider this possibility.

16. Ibid.

17. While using panel data can increase power in unit root tests, given the strong rejection of the unit root hypothesis for nearly all states, the use of panel tests would not provide any additional information as compared to our univariate tests. For example, using the panel unit root test of Im, Pesaran, and Shin (2003) a rejection of the null indicates only that at least one state is stochastically converging.

18. Carlino and Mills (1996) note that while state per capita incomes were converging throughout 1929-1990; they diverged from 1978 to 1988. In addition, most state income convergence occurred prior to 1946. Taken together, these facts strengthen our findings that the period surrounding 1970 characterized a structural break. For example, in spite of diverging per capita incomes in the post-1970 period, per capita emissions were converging in more states than before 1970 . 


\section{REFERENCES}

Andreoni, James and Arik Levinson. 2001. "The Simple Analytics of the Environmental Kuznets Curve," Journal of Public Economics, 80, 269-286.

Arora, Seema and Timothy N. Cason. 1999. "Do Community Characteristics Determine Environmental Outcomes? Evidence from the Toxics Release Inventory," Southern Economic Journal, 65, 691-716.

Arrow, K., B. Bolin, R. Costanza, P. Dasgupta, C. Folke, C. Holling, B-O. Jansson, S. Levin, K. -G. Maler, C. Perrings, and D. Pimentel, 1995. "Economic Growth, Carrying Capacity, and the Environment," Science, 268, 520-521.

Azomahou, T., F. Laisney, and P. Nguyen Van, 2006. "Economic Development and CO2 Emissions: A Nonparametric Panel Approach," Journal of Public Economics, 90, 1347-1363.

Barro, Robert J., and Xavier Sala-i-Martin. 1991. "Convergence across States and Regions," Brookings Papers on Economic Activity, 1, 107-158.

Break, George. 1967. Intergovernmental Fiscal Relations in the United States. Washington, D.C.: The Brookings Institution.

Brock, William A., and M. Scott Taylor. 2004. "Economic Growth and the Environment: Matching the Stylized facts,"Working Paper, Department of Economics, University ofWisconsin-Madison.

Brooks, Nancy and Rajiv Sethi. 1997. "The Distribution of Pollution: Community Characteristics and Exposure to Air Toxics," Journal of Environmental Economics and Management, 32, 233250.

Carlino, Gerald and Leonard Mills. 1993. "Are U.S. Regional Economies Converging? A Time Series Analysis," Journal of Monetary Economics, 32, 335-346.

1996. "Convergence and the U.S. State: A Time-Series Analysis," Journal of Regional Science, 36, 597-616.

Cumberland, John H. 1980. "Efficiency and Equity in Interregional Environmental Management," Review of Regional Studies, 10, 1-9.

Evans, Paul and Georgios Karras. 1996a. "Convergence Revisited," Journal of Monetary Economics, 37, 249-265.

1996b. "Do Economies Converge? Evidence from a Panel of U.S. States," The Review of Economics and Statistics, 78, 384-388.

Friedman, Milton. 1992. "Do Old Fallacies Ever Die?" Journal of Economic Literature, 30, 2129_ 2132.

Gianessi, Leonard P., Henry M. Peskin, and Edward Wolff. 1979. "The Distributional Effects of Uniform Air Pollution Policy in the United States," Quarterly Journal of Economics, 93, 281301. 
Grossman, Gene M., and Alan B. Krueger. 1995. "Economic Growth and the Environment," Quarterly Journal of Economics, 112, 353-378.

Hamilton, James T. 1995. "Testing for Environmental Racism: Prejudice, Profits, Political Power?,"Journal of Policy Analysis and Management, 14, 107-132.

Im, Kyung So, Hashem M. Pesaran, and Yongcheol Shin, 2003. "Testing for Unit Roots in Heterogeneous Panels,” Journal of Econometrics, 115, 53-74.

Jeppesen, Tim, John A. List, and Henk Folmer. 2002. "Environmental Regulations and New Plant Location Decisions: Evidence from a Meta-Analysis," Journal of Regional Science, 42, 1949.

Krugman, Paul. 1997. "What Should Trade Negotiators Negotiate About?" Journal of Economic Literature, 35, 113-120.

Lee, Junsoo, and Mark C. Strazicich. 2001. "Break Point Estimation and Spurious Rejections with Endogenous Unit Root Tests," Oxford Bulletin of Economics and Statistics, 63, 535-558.

_. 2003. "Minimum LM Unit Root Test with Two Structural Breaks," The Review of Economics and Statistics, 85, 1082-1089.

—. 2004. "MinimumLMUnit Root Test with One Structural Break,"Working Paper, Department of Economics, Appalachian State University.

List, John A., 1999. "Have Air Pollutant Emissions Converged Amongst US Regions? Evidence from Unit-Root Tests," Southern Economic Journal, 66, 144-155.

List, John A., and Craig A. Gallet. 1999. "The Environmental Kuznets Curve: Does one size fit all?” Ecological Economics, 31, 409-424.

List, John A. and Shelby Gerking. 2000. "Regulatory Federalism and U.S. Environmental Policies," Journal of Regional Science August, 40, 453-471.

Loewy, Michael B. and David H. Papell. 1996. "Are U.S. Regional Incomes Converging? Some Further Evidence," Journal of Monetary Economics, 38, 587-598.

MacKinnon, James G. 1991. "Critical Values for Cointegration Tests," in Robert F. Engle, and CliveW. J. Granger (eds.), Long-run Economic Relationships: Readings in Cointegration.

Oxford: Oxford University Press in Chapter 13.

Mankiw, N., David Romer Gregory, and David N. Weil. 1992. "A Contribution to the Empirics of Economic Growth,” Quarterly Journal of Economics, 107, 407-438.

Millimet, Daniel, John A. List, and Thanasis Stengos. 2003. "The Environmental Kuznets Curve: Real Progress or Misspecified Models?" Review of Economics and Statistics, 85, pp. 1038-1047. 
Millimet, Daniel L. and John A. List. 2003. "A Natural Experiment on the 'Race to the Bottom' Hypothesis: Testing for Stochastic Dominance in Temporal Pollution Trends," Oxford Bulletin of Economics \& Statistics, 65, 395-420.

Musgrave, Richard A. 1959. The Theory of Public Finance: A Study in Public Economy. New York: McGraw-Hill.

Ng, Serena, and Pierre Perron. 1995. "Unit Root Tests in ARMA Models with Data-Dependent Methods for the Selection of the Truncation Lag," Journal of the American Statistical Association, 90, 269-281.

Nunes, Luis C., Paul Newbold, and Chung-Ming Kuan. 1997. "Testing for Unit Roots with Breaks: Evidence on the Great Crash and the Unit Root Hypothesis Reconsidered," Oxford Bulletin of Economics and Statistics, 59, 435-448.

Oates, Wallace E. 1991. Studies in Fiscal Federalism. Brookfield: Edward Elgar.

- 2002. "A Reconsideration of Environmental Federalism," in J. A. List, and A. de Zeeuw (eds.), Recent Advances in Environmental Economics. Cheltenham: Edward Elgar.

Oates, Wallace E., and Robert M. Schwab. 1988. "Economic Competition Among Jurisdictions: Efficiency Enhancing or Distortion Inducing?” Journal of Public Economics, 35, 333-354.

Perron, Pierre. 1989. "The Great Crash, the Oil Price Shock, and the Unit Root Hypothesis," Econometrica, 57, 1361-1401.

Portney, Paul R., ed., 1990. Public Policies for Environmental Protection. Washington, D.C.: Resources for the Future.

Quah, Danny. 1993. "Galton's Fallacy and the Tests of the Convergence Hypothesis," Scandinavian Journal of Economics, 95, 427-443.

- 1996. "Empirics for Economic Growth and Convergence," European Economic Review, 40, 1353-1375.

Solow, Robert M. 1956. "A Contribution to the Theory of Economic Growth," Quarterly Journal of Economics, 70, 65-94.

Stokey, Nancy L. 1998. "Are there limits to growth?" International Economic Review, 39, 1-31. Strazicich, Mark C., and John A. List. 2003. "Are CO2 Emission Levels Converging Among Industrial Countries?" Environmental and Resource Economics, 24, 263-271.

Tiebout, Charles M. 1956. "A Pure Theory of Local Expenditures," Journal of Political Economy, 64, 416-424.

Tomljanovich, Marc and Timothy J. Vogelsang. 2002. "Are U.S. Regions Converging? Using New Econometric Methods to Examine Old Issues," Empirical Economics, 27, 49-62.

U.S. Environmental Protection Agency, 1997. The Benefits and Costs of the Clean Air Act, 1970 to 1990. EPA-410/R-97-002. Washington, D.C. 
U.S. Environmental Protection Agency, Office of Air Quality Planning and Standards. 1995. National Air Pollutant Emission Trends, 1900-1994. EPA-454/R-95-011. Research Triangle Park, NC.

-1998. National Air Pollutant Emission Trends, Procedures Document, 1900-1996. EPA454/R-98-008. Washington, D.C.

Webber, Don J., Paul White, and David O. Allen. 2005. "Income Convergence Across U.S. States: An Analysis using Measures of Concordance and Discordance," Journal of Regional Science, 45, 565-589.

Wellisch, Dietmar. 2000. Theory of Public Finance in a Federal State. Cambridge: Cambridge University Press.

Wilson, John D. 1996. "Capital Mobility and Environmental Standards: Is There a Theoretical Basis for a Race to the Bottom?" in Jagdish N. Bhagwati and Robert E. Hudec (eds.), Fair Trade and Harmonization: Prerequisites for Free Trade? Volume 1: Economic Analysis. Cambridge, MA: The MIT Press in Chapter 10.

—. 1999. "Theories of Tax Competition," National Tax Journal, 52, 269-304.

Zivot, Eric and Donald W. K. Andrews. 1992. "Further Evidence on the Great Crash, the OilPrice Shock and the Unit Root Hypothesis," Journal of Business and Economic Statistics, 10, 251-270. 


\section{APPENDIX}

\section{An Example of Convergence and Divergence of Pollution}

This appendix serves as an illustration of the point made in the text that, in theory, pollution levels may converge or diverge over time. We use a simple Solow growth model to make this point. Along a balanced growth path in such a model, the growth rate of per capita income $\hat{y}^{*}$ and capital $\hat{k}^{*}$ equals the exogenous rate of technical change, $g$. When economies are off the balanced path, conditional convergence of incomes occurs

$$
\hat{y}=g+\lambda\left(\ln y-\ln y^{*}\right),
$$

where $\lambda=(\rho-1)(\delta+n+g)<0$. In (A1), $y$ is per capita income, $\rho<1$ is a production parameter, $\delta$ is the depreciation rate of capital, and $n$ is the growth rate of population.

How does income convergence affect the pollution path over time? Assume that a social planner in state $j$ maximizes utility defined as $U_{\mathrm{j}}=C_{\mathrm{j}}-z P_{\mathrm{j}}$, where $C_{\mathrm{j}}$ is aggregate consumption in state $j, P_{\mathrm{j}}$ is the level of pollution, and $z$ is a preference parameter. Omitting subscripts, the budget restriction for each individual reads as follows: $y=c+b+i$, or $c+b=(1-s) y$, where $b$ is per capita abatement effort and $s$ is the exogenous savings rate. Aggregate consumption is defined as per capita consumption $c$ multiplied by the number of people in the state, or $C=L_{0} \mathrm{e}^{\mathrm{nt}} c$ ( $L_{0}$ is the initial population in the state). The state government chooses optimal per capita consumption $c^{*}$ and abatement levels $b^{*}$, ignoring spillover costs affecting neighboring states.

Flow pollution is a byproduct of consumption but may be mitigated by abatement. In what follows, we adopt the specification by Andreoni and Levinson (2001)

$$
P=C-C^{\alpha} B^{\beta},
$$

where $\mathrm{B}$ represents aggregate abatement effort $\left(B=L_{0} \mathrm{e}^{\mathrm{nt}} b\right)$, so $C^{\alpha} B^{\beta}$ represents total abatement. Aggregate utility may be written as $U=C-z\left(C-C^{\alpha} B^{\beta}\right)$, and upon setting $\mathrm{z}=1$, this simplifies to $U=C^{\alpha} B^{\beta}$. The assumption that $z=1$ does 
not affect the qualitative nature of the results, but influences the optimal "level" of consumption and abatement. If the planner maximizes per capita utility at the state level, subject to the budget constraint, the optimal solution is defined as

$$
\begin{gathered}
c^{*}=\frac{\alpha}{\alpha+\beta} y(1-s), \text { and } \\
b^{*}=\frac{\beta}{\alpha+\beta} y(1-s) .
\end{gathered}
$$

Upon substituting (A3) and (A4) into the pollution function and assuming that the economy is on a balanced growth path, the optimal quantity of pollution is a function of income, population, technical parameters $(\alpha, \beta)$, and other parameters $(s, g)$

$$
P^{*}(y)=L_{0} e^{n t}\left[\frac{\alpha}{\alpha+\beta} y_{0}^{*} e^{g t}(1-s)-\left(\frac{\alpha}{\alpha+\beta}\right)^{\alpha}\left(\frac{\beta}{\alpha+\beta}\right)^{\beta}(1-s)^{\alpha+\beta}\left(y_{0}^{*} e^{g t}\right)^{\alpha+\beta}\right] .
$$

While this formulation is slightly different from the model developed by Andreoni and Levinson (specifically, both income and population are growing over time), the main findings are identical-assuming increasing returns to scale in abatement $(\alpha+\beta>1)$, the EKC obtains: $\partial P^{*} / \partial y^{*} \geq 0$ and $\partial^{2} P^{*} / \partial y^{* 2} \leq$ 0 . From (A5) we obtain three insights about the convergence of pollutants.

First, note that (A5) implies $P^{*} \rightarrow-\infty$ as $y(t) \rightarrow \infty$, which is not feasible. When adding $P \geq 0$ as an additional restriction, we can divide the dynamics of pollution into two phases. First, pollution levels are positive (an interior solution) and for sufficiently low initial income levels will describe an invertedU shape over time. Later, pollution becomes zero (a corner solution) and remains zero thereafter. In the long run, absolute convergence of pollution is expected to occur at the zero pollution level.

Second, during the stage with an interior solution $(P>0)$ we can solve for the "balanced pollution path" as follows

$$
\dot{P}^{*}(y)=n P+\left[\mu y-(\alpha+\beta) \theta(y)^{\alpha+\beta}\right] g L_{0} e^{n t},
$$

where $\mu=\frac{\alpha(1-s)}{\alpha+\beta}>0$ and $\theta=\left(\frac{\alpha}{\alpha+\beta}\right)^{\alpha}\left(\frac{\beta}{\alpha+\beta}\right)^{\beta}(1-s)^{\alpha+\beta}>0$. The rate of change of pollution along the interior balanced path is defined as

$$
\hat{P}^{*}=\frac{P^{*}}{P^{*}}=n+g\left[1+\frac{(1-\alpha-\beta) \theta y^{\alpha+\beta}}{\mu y-\theta(y)^{\alpha+\beta}}\right] .
$$

With $\alpha+\beta>1$, it follows from (A7) that the sign of the growth rate of pollution is ambiguous - for low-income levels the balanced pollution path is upward sloping, but as income increases the balanced pollution path levels off and eventually slopes downward (until it reaches the border where $P=0$, after which $P=0$ henceforth). Note that the rate of change of pollution is also a function of the "domestic" parameters, such as the propensity to save and production 
parameters. ${ }^{19}$ These parameters affect the level of the balanced growth path of income, and the rate of change of the balanced pollution path.

Pollution levels are expected to converge conditionally to the balanced pollution path when economies are off the balanced income path

$$
\hat{P}=\left(\hat{P}^{*}\right)_{y=y *}+\frac{d \hat{P}}{d y}\left(y-y^{*}\right) .
$$

To analyze out-of-equilibrium pollution levels we need to determine $\frac{d \tilde{P}}{d y}$. Differentiating the expression for the pollution growth rate in (A7) gives us

$$
\frac{d \hat{P}}{d y}=\frac{-g \theta(1-\alpha-\beta)^{2} \mu y^{\alpha+\beta}}{\left[\mu y-\theta(y)^{\alpha+\beta}\right]^{2}}<0 .
$$

The dynamics of out-of-equilibrium behavior of pollution may be summarized as

$$
\hat{P}=\left(\hat{P}^{*}\right)_{y=y_{*}}+\frac{-g \theta \mu(1-\alpha-\beta)^{2} y^{\alpha+\beta}}{\left[\mu y-\theta(y)^{\alpha+\beta}\right]^{2}}\left(y-y^{*}\right) .
$$

We can now confirm that pollution levels converge towards the balanced path over time. If income is below (above) the balanced growth path, the growth rate of pollution exceeds (falls short of) the growth rate along the equilibrium pollution path. ${ }^{20}$

Third, and discussed in the main text, for interior solutions $(P>0)$, absolute pollution levels may converge or diverge depending on income levels-both during the approach to the balanced growth paths and along balanced growth paths.

\footnotetext{
${ }^{19}$ When the parameters $\alpha, \beta, s, n$, and $z$ take on different values for different states, income is expected to "conditionally" converge to a constant differential.

${ }^{20}$ The convergence process for pollution is slightly more complex than the convergence of income. Recall that the relationship between pollution and income is described by an inverted $\mathrm{U}$ for $\alpha+\beta>1$. Thus, the time path for pollution may be upward-or downward-sloping depending on the associated income level - hence the ambiguity in (A7). If the pollution path is downward-sloping, (A10) should be interpreted as follows: if actual income is lower than equilibrium income, (i) income will grow faster than along the balanced growth path, and (ii) pollution will be reduced more slowly than along the balanced growth path. If income exceeds income on the balanced growth path, (i) income will grow more slowly but (ii) pollution levels will be reduced faster than along the relevant equilibrium path. The pollution responses will be reversed if the economy is (still) located on the upward-sloping portion of the EKC.
} 